\title{
Effect of hot forging in the ordered phase field on microstructure and mechanical properties of $\beta$-solidifying $\gamma$-TiAl alloys
}

\author{
V.M. Imayev ${ }^{\dagger}$ A. A. Ganeev, T. I. Nazarova, R. M. Imayev \\ †vimayev@mail.ru
}

Institute for Metals Superplasticity Problems RAS, 39 S. Khalturin St., Ufa, 450001, Russia

\begin{abstract}
Effect of hot forging at lower temperatures, in the ordered $\alpha_{2}+\gamma+\beta_{0} / \alpha_{2}+\gamma$ phase field, followed by heat treatment on the microstructure and tensile properties has been studied for three $\beta$-solidifying $\gamma$-TiAl alloys. The alloy compositions were Ti-45Al-5Nb-1Mo-0.2B, Ti-43.7Al-4.2Nb-0.5Mo-0.2C-0.2B and Ti-44Al-5Nb-0.2B (at.\%). The phase transformation sequences were defined for the alloys. Hot forging procedures for the Ti-45Al and Ti-43.7 Al based alloys included forging in the temperature range of the $\alpha+\gamma+\beta\left(\beta_{0}\right) / \alpha+\alpha_{2}+\gamma+\beta\left(\beta_{0}\right)$ and $\alpha_{2}+\gamma+\beta_{0}$ phase fields. This led to refined microstructures due to occurrence of dynamic recrystallization and globularization processes. The as-forged alloys showed excellent superplastic properties. Particularly, superior superplastic properties ( $E l \gg 1000 \%$ and low flow stresses), never reached in $\gamma$-TiAl alloys, were obtained for the Ti-43.7 Al based alloy in the temperature range of $900-1000^{\circ} \mathrm{C}$. The Ti-44Al based alloy was subjected to upset forging using a small strain value in the temperature range of the $\alpha_{2}+\gamma$ phase field. All forged alloys were further subjected to two-stage annealing in the $\alpha+\gamma+\beta\left(\beta_{0}\right)$ and $\alpha_{2}+\gamma+\beta_{0}$ or $\alpha_{2}+\gamma$ phase fields. As a result, refined duplex microstructures were obtained in the alloys. Tensile tests were performed for the forged and heat treated alloys. They showed quite reasonable tensile properties as compared with those obtained in similar alloys after high-temperature hot forging followed by heat treatment. Particularly, the Ti-45Al-5Nb-0.2B alloy in the duplex condition exhibited $E l=3.1 \%$ and UTS $=860 \mathrm{MPa}$ at room temperature and $E l=6.5 \%$ and $\mathrm{UTS}=790 \mathrm{MPa}$ at $700^{\circ} \mathrm{C}$.
\end{abstract}

Keywords: gamma titanium aluminides, $\beta$-solidifying $\gamma$-TiAl alloys, hot forging, fine-grained microstructure, mechanical properties.

\section{Introduction}

Intermetallic alloys based on the $\gamma$-TiAl phase are being applied as light-weight high-temperature materials $[1,2]$. Nevertheless, the manufacturing technologies of these alloys are still very expensive because of low castability, machinability and hot workability of $\gamma$-TiAl alloys. To facilitate the manufacturing technologies of $\gamma$-TiAl alloys some years ago so-called $\beta$-solidifying alloys alloyed with Nb, Mo, B (so called TNM alloys) and sometimes with other elements have been developed [2-7]. In contrast to peritectically solidifying alloys the $\beta$-solidifying TNM (or near TNM) alloys offer a number of advantages such as: i) improved chemical homogeneity (due to avoiding peritectic reactions), ii) the opportunity for grain refinement in the course of the solid $\beta \rightarrow a$ phase transformation, iii) no sharp casting texture. Nevertheless, in spite of the presence of the $\beta\left(\beta_{\mathrm{o}}\right)$ phase and the refined as-cast structure, TNM alloys possess rather low hot workability at temperatures below $1150-1200^{\circ} \mathrm{C}$ (i.e. in the ordered phase field). Therefore, hot forging of TNM or similar alloys is typically carried out at $1200-1250^{\circ} \mathrm{C}$ under isothermal or near isothermal conditions [8-11]. This often requires the use of expensive Mo-based dies and a protective atmosphere [8]. Canned extrusion of TNM or TNB $\gamma$-TiAl alloys is performed at $1200-1300^{\circ} \mathrm{C}[12-14]$ that as seems can lead to sharp texture and to banded and inhomogeneous structures $[13,14]$.
Instead or additionally to high-temperature hot working (in the $\alpha+\gamma+\beta\left(\beta_{\mathrm{o}}\right)$ or $\alpha+\beta$ phase field) it makes sense to use hot forging at lower temperatures in the ordered $\alpha_{2}+\gamma+\beta_{\mathrm{o}}$ or $\alpha_{2}+\gamma$ phase filed [15-19]. That offers a number of advantages: i) this is cheaper because the forging dies made of a Ni-base superalloy without any protective atmosphere can be used; ii) more strain energy can be imparted using smaller strain values; iii) finer microstructure can be reached as a result of recrystallization and globularization processes. At the same time, lower hot workability can be overcome through preliminary conversion of the as-cast structure into finegrained during forging at higher temperatures or via using small strain values to avoid failure during forging.

The aim of the present work was achievement of properly balanced mechanical properties in TNM (or similar) $\gamma$-TiAl based alloys with emphasis on ductility via using hot forging at lower temperatures in the ordered phase field. Three $\beta$-solidifying $\gamma$-TiAl alloys were taken and three different processing routes including forging in the $\left(\alpha_{2}+\gamma+\beta_{0}\right)$ or $\left(\alpha_{2}+\gamma\right)$ phase field followed by heat treatment were used. The essential aim of the present study was to evaluate the tensile properties of the forged and heat treated alloys in comparison with those available in the literature data.

\section{Materials and experimental}

Three $\gamma$-TiAl alloys were taken as starting materials. The Ti-45Al-5Nb-1Mo-0.2B and Ti-43.7Al-4.2Nb-0.5Mo-0.2C-0.2B 
alloys were manufactured by vacuum arc remelting and supplied from GfE Metalle und Materialien, Germany as cast ingots of $\varnothing 120 \mathrm{~mm} \times 180 \mathrm{~mm}$ and $\varnothing 95 \mathrm{~mm} \times 180 \mathrm{~mm}$, respectively. The Ti-44Al-5Nb-0.2 alloy was manufactured by arc-melting under argon atmosphere as an ingot with an approximate size of $\varnothing 45 \mathrm{~mm} \times 15 \mathrm{~mm}$. Table 1 describes schematically the processing routs applied for the alloys. For the sake of simplicity, the alloys under study are designated throughout the text as Ti45, Ti43.7 and Ti44, respectively.

The Ti45 and Ti43.7 alloys were first subjected to quasiisothermal canned hot forging. In so doing, the as-cast ingots encapsulated in steel cans were preheated at $1200^{\circ} \mathrm{C}$, the forging dies made of a Ni-base superalloy were preheated at $950^{\circ} \mathrm{C}$. During forging the real temperature of the workpiece was not strictly controlled but appreciably reduced. The forged workpiece of the Ti43.7 alloy was then decanned and small workpieces were cut from the workpiece, which were further subjected to isothermal $3 \mathrm{D}$ forging at $T=950^{\circ} \mathrm{C}$. The Ti44 alloy in as-cast condition was subjected to upset forging using a small strain value under isothermal conditions at $T=950^{\circ} \mathrm{C}$. Thus, the highest total strain value was imparted in the case of the Ti43.7 alloy $(e \approx 4)$, a lower strain value was imparted in the case of the Ti45 alloy $(e \approx 1.2)$ and the lowest strain was in the case of the Ti44 alloy $(e \approx 0.2)$. The forged alloys were annealed in two stages as shown in Table 1. Furnace cooling was used to avoid appearance of non-equilibrium phases like the $\omega$-phase and to have the most equilibrium microstructural conditions. Note that the hot forging routes applied for the Ti45 and Ti43.7 alloys were based on the hot workability criterion and the opportunity to forge different $\gamma$-TiAl alloys in the ordered phase field $[18,19]$. In the case of the Ti44 alloy effect of a small strain value in the ordered phase field followed by heat treatment on the microstructure and tensile properties was evaluated.

To evaluate the tensile properties of the alloys, flat samples with a gauge size of $10 \times 5 \times 2 \mathrm{~mm}^{3}$ were tested at room and elevated temperatures. The tensile axis was always oriented perpendicular to the last forging direction. The tensile tests were performed in air.

Differential scanning calorimetric (DSC) measurements were made to determine the phase transformation sequences. Microstructural examination was carried out using scanning electron microscopy in backscattering electron mode (SEM, BSE). Before study by SEM, the specimen surfaces were polished. BSE images were used to define the grain/lamellar colonies size, the volume fractions of lamellae remnants and the $\beta\left(\beta_{0}\right)$ phase. The alloy composition was measured by energy dispersive $\mathrm{X}$-ray (EDX) analysis system.

\section{Results and discussion}

Fig. 1 represents BSE images of the alloys in the initial as-cast conditions. One can see that refined nearly lamellar structures typical of TNM based gamma alloys were obtained. The alloys contained different amount of the bright $\beta\left(\beta_{\mathrm{o}}\right)$ phase depending on the $\beta$ stabilization of alloying elements. The $\beta\left(\beta_{0}\right)$ phase volume fraction was defined as about 5 and 0.5 pct in the Ti45 and Ti43.7 alloys, respectively. The Ti44 alloy was free of Mo and contained only the metastable $\beta\left(\beta_{\mathrm{o}}\right)$ phase.
Considering the as-cast microstructures, taking into account DSC measurements and literature data $[2,5,6,8,20]$, the phase transformation sequences were defined. For the Ti45 alloy it is as follows: $\mathrm{L} \rightarrow \mathrm{L}+\beta \rightarrow \beta \rightarrow \beta+\alpha \rightarrow$ $\rightarrow \alpha+\gamma+\beta\left(\beta_{0}\right) \rightarrow \alpha+\alpha_{2}+\gamma+\beta\left(\beta_{0}\right) \rightarrow \alpha_{2}+\gamma+\beta_{o}$, where $\alpha_{2}$ and $\beta_{\mathrm{o}}$ are the ordered phases. For the Ti43.7 alloy containing a carbon, which is known as a strong a stabilizer, the phase transformation sequence is the following: $\mathrm{L} \rightarrow \mathrm{L}+\beta \rightarrow \beta \rightarrow$ $\rightarrow \beta+\alpha \rightarrow \alpha \rightarrow \alpha+\gamma \rightarrow \alpha+\gamma+\beta\left(\beta_{0}\right) \rightarrow \alpha+\alpha_{2}+\gamma+\beta\left(\beta_{0}\right)$ $\rightarrow \alpha_{2}+\gamma+\beta_{0}$. For the Ti44 alloy the following phase transformation sequence was earlier determined [5]: $\mathrm{L} \rightarrow \mathrm{L}+\beta \rightarrow \beta \rightarrow \beta+\alpha \rightarrow \alpha+\beta_{\mathrm{m}} \rightarrow \alpha+\gamma+\beta_{\mathrm{m}} \rightarrow \alpha_{2}+\gamma+\beta_{\mathrm{m}}$, where $\beta_{\mathrm{m}}$ is the remaining metastable $\beta\left(\beta_{\mathrm{o}}\right)$ phase. The $\alpha_{2}$ disordering temperature for the alloys under study was defined in the range of $1160-1190^{\circ} \mathrm{C}$. The $\beta_{\mathrm{o}}$ disordering temperature is about $1210^{\circ} \mathrm{C}$ [8]. Thus, the forging procedures for the Ti45 and Ti43.7 alloys were performed first in the three/four phase fields and then in the ordered three phase field $\alpha_{2}+\gamma+\beta_{0}$. The as-cast Ti44 alloy was subjected to upset forging at lower temperatures in the $\alpha_{2}+\gamma+\beta_{\mathrm{m}}$ phase field. In so doing, the metastable $\beta$ phase was dissolved. Post-forging annealing of all alloys was performed in the $\alpha+\gamma+\beta\left(\beta_{\mathrm{o}}\right)$ and $\alpha_{2}+\gamma+\beta_{0} / \alpha_{2}+\gamma$ phase fields.

Fig. 2 shows the BSE images obtained after hot forging of the Ti45 and Ti43.7 alloys (the Ti44 alloy was not examined). Hot forging led to microstructure refinement due to occurrence of dynamic recrystallization and globularization processes. In the Ti45 alloy the microstructure was near completely recrystallized, whereas in the Ti43.7 alloy the lamellae remnants occupied about 40 vol.\% in spite of a larger strain imparted during forging. After post-forging heat treatment the duplex structures were obtained in the alloys (Fig. 3). Refined duplex structures with a similar grain/colony size were obtained in the Ti45 and Ti43.7 alloys. In the Ti44 alloy the duplex structure was coarser and the fraction of lamellar colonies was much higher.

Table 2 shows the microstructural characteristics of the alloys after hot forging and heat treatment. One can see that refined microstructures were attained after forging in the Ti45 and Ti43.7 alloys. A slower kinetics of recrystallization and globularization processes in the Ti43.7 alloy can be ascribed to a higher content of the $\alpha_{2}$ phase and a higher stability of the lamellar structure due to the carbon addition. Postforging heat treatment led to formation of duplex structures. The duplex structure in the Ti44 alloy was appreciably coarser and contained a higher amount of the lamellar colonies than in the case of the Ti45 and Ti43.7 alloys. This can be explained first of all by a smaller strain value imparted during upset forging. Note that the volume fraction of the $\beta\left(\beta_{\mathrm{o}}\right)$ phase was reduced during processing. In the Ti45 alloy the amount of the $\beta\left(\beta_{0}\right)$ phase after postforging heat treatment was defined as $1.3 \%$, in the Ti43.7 the $\beta\left(\beta_{\mathrm{o}}\right)$ phase content was near zero. In the Ti44 alloy the metastable $\beta\left(\beta_{\mathrm{o}}\right)$ phase was completely dissolved that was a result of a lower $\beta$ stabilization in this alloy.

In the as-forged conditions the Ti45 and Ti43.7 alloys demonstrated excellent superplastic properties in the temperature range of $900-1000^{\circ} \mathrm{C}[15,17,21]$ (Table 3). Particularly, superior superplastic properties, never reached in $\gamma$-TiAl alloys, were obtained for the Ti43.7 alloy. As has 
Table 1. Processing of the alloys under study.

\begin{tabular}{|c|c|}
\hline Alloy compositions, at.\% & Processing \\
\hline Ti-45Al-5Nb-1Mo-0.2B [16] & $\begin{array}{r}\text { VAR }+ \text { canned hot forging }\left(T_{p}=1200^{\circ} \mathrm{C}, T_{\text {die }}=950^{\circ} \mathrm{C}, e \approx 1.2, \dot{\varepsilon} \sim 10^{-2}-10^{-1} \mathrm{~s}^{-1}\right)+\text { annealing at } \\
1250^{\circ} \mathrm{C}(2 \mathrm{~h}), \mathrm{FC} \text { and } 900^{\circ} \mathrm{C}(4 \mathrm{~h})\end{array}$ \\
\hline Ti-43.7Al-4.2Nb-0.5Mo-0.2C-0.2B $[17]$ & $\begin{array}{c}\text { VAR + the same canned forging }(e \approx 1.2)+\text { cutting into smaller workpieces }+ \text { isothermal } 3 \mathrm{D} \\
\text { forging }\left(T=950^{\circ} \mathrm{C}, e \approx 2.8, \dot{\varepsilon} \sim 10^{-3} \mathrm{~s}^{-1}\right)+\text { annealing at } 1200^{\circ} \mathrm{C}(2 \mathrm{~h}), \mathrm{FC} \text { and } 900^{\circ} \mathrm{C}(4 \mathrm{~h})\end{array}$ \\
\hline Ti-44Al-5Nb-0.2B & $\begin{array}{r}\text { Arc-melting under argon atmosphere }+ \text { isothermal upset forging }\left(T=950^{\circ} \mathrm{C}, e \approx 0.2,\right. \\
\left.\dot{\varepsilon} \sim 10^{-3}-10^{-4} \mathrm{~s}^{-1}\right)+ \text { annealing at } 1250^{\circ} \mathrm{C}(2 \mathrm{~h}), \mathrm{FC} \text { and } 900^{\circ} \mathrm{C}(4 \mathrm{~h})\end{array}$ \\
\hline
\end{tabular}

VAR - vacuum arc remelting, $T_{p}-$ the preheating temperature of the canned workpieces, $T_{\text {die }}-$ the temperature of forging dies, FC - furnace cooling.

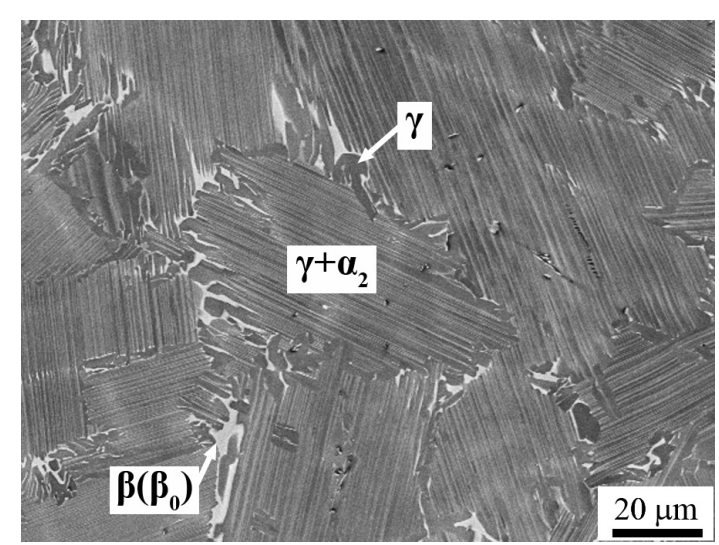

a

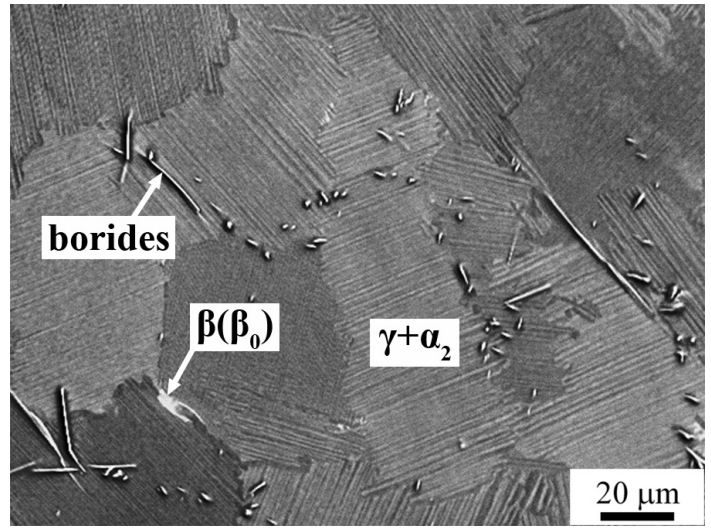

$\mathrm{b}$

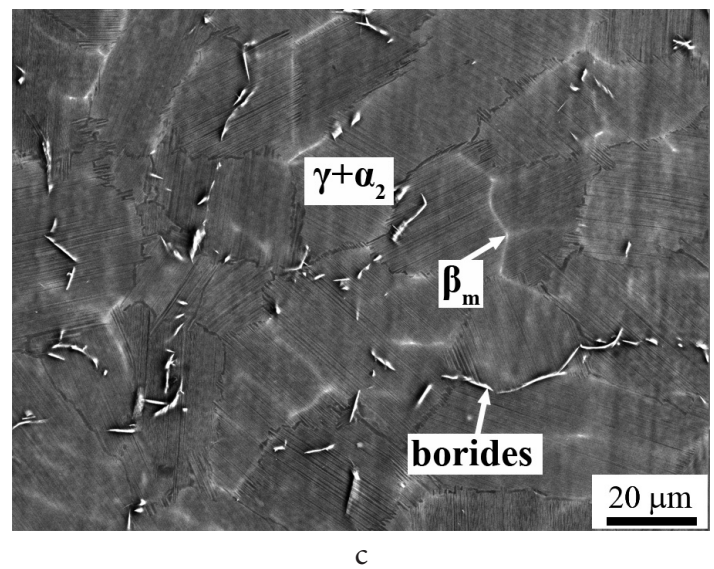

Fig. 1. BSE images of the alloys in the initial as-cast conditions: Ti-45Al-5Nb-1Mo-0.2 (a), Ti-43.7Al-4.2Nb-0.5Mo-0.2C-0.2B (b), and Ti-44Al-5Nb-0.2B (c). Different microstructure constituents are marked and arrowed.

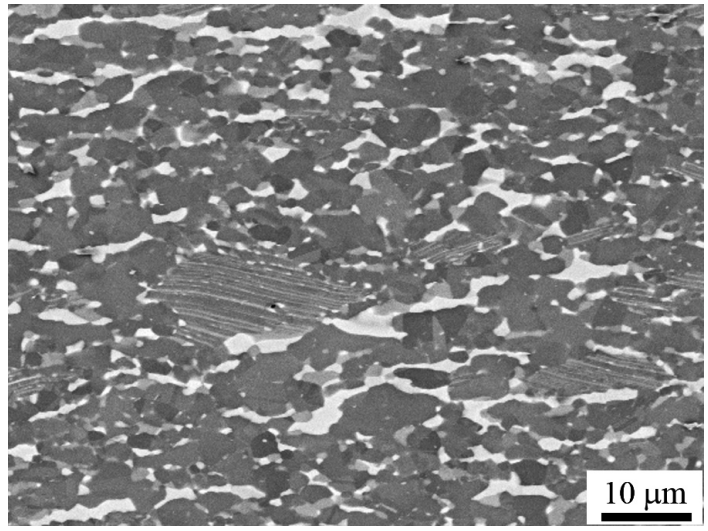

a

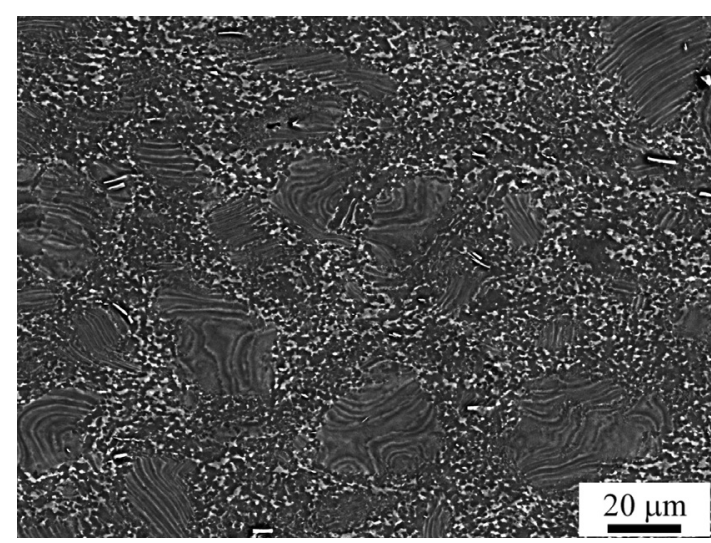

b

Fig. 2. BSE images obtained after hot forging of the alloys: Ti-45Al-5Nb-1Mo-0.2 (a), Ti-43.7Al-4.2Nb-0.5Mo-0.2C-0.2B (b). 
Table 2. Microstructure characteristics of the alloys after hot forging and heat treatment.

\begin{tabular}{|c|c|}
\hline Alloy & Microstructures obtained after processing \\
\hline Ti-45Al-5Nb-1Mo-0.2B & $\begin{array}{l}\text { Forging: FG, } d=5 \mu \mathrm{m}+10 \text { vol. } \% \text { lamellae remnants, } 3-4 \text { vol. } \% \beta\left(\beta_{\mathrm{o}}\right) \\
\text { Forging + HT: DP (FG, } d=8 \mu \mathrm{m}+20 \text { vol. } \% \text { lamellar colonies), } 1.3 \text { vol. } \% \beta\left(\beta_{\mathrm{o}}\right)\end{array}$ \\
\hline Ti-43.7Al-4.2Nb-0.5Mo-0.2C-0.2B & $\begin{array}{l}\text { Forging: FG, } d=0.8 \mu \mathrm{m}+40 \text { vol. } \% \text { lamellae remnants, } d_{L}=5-40 \mu \mathrm{m}, 0.5 \text { vol. } \% \beta\left(\beta_{\mathrm{o}}\right) \\
\text { Forging + HT: DP (FG, } d=6 \mu \mathrm{m}+20 \text { vol. } \% \text { lamellar colonies }),<0.5 \text { vol. } \% \beta\left(\beta_{\mathrm{o}}\right)\end{array}$ \\
\hline Ti-44Al-5Nb-0.2B & $\begin{array}{c}\text { Forging: not evaluated } \\
\left.\text { Forging + HT: DP (FG, } d=3-12 \mu \mathrm{m}+60 \text { vol. } \% \text { lamellar colonies, } d_{L}=15-50 \mu \mathrm{m}\right), V_{\beta(\beta \mathrm{o})}-\mathrm{n} / \mathrm{a}\end{array}$ \\
\hline
\end{tabular}

FG - fine-grained, HT - heat treatment, DP - duplex structure, $d-$ the size of fine grains, $d_{L}-$ the size of lamellar colonies/lamellae remnants.

Table 3. Superplastic properties of the Ti-45Al-5Nb-1Mo-0.2 and Ti-43.7Al-4.2Nb-0.5Mo-0.2C-0.2B alloys in the forged conditions.

\begin{tabular}{|c|c|c|}
\hline Alloy & $T,{ }^{\circ} \mathrm{C} / \dot{\varepsilon}$, & Tensile properties \\
\hline \multirow{2}{*}{ Ti-45Al-5Nb-1Mo-0.2B [15] } & $1000^{\circ} \mathrm{C} / 8.3 \times 10^{-4} \mathrm{~s}^{-1}$ & $\delta=1000 \%, \sigma_{\mathrm{UTS}}=95 \mathrm{MPa}$ \\
& $950^{\circ} \mathrm{C} / 8.3 \times 10^{-4} \mathrm{~s}^{-1}$ & $\delta=560 \%, \sigma_{\mathrm{UTS}}=190 \mathrm{MPa}$ \\
\hline & $1000^{\circ} \mathrm{C} / 8.3 \times 10^{-4} \mathrm{~s}^{-1}$ & $\delta=2860 \%, \sigma_{30 \%}=25 \mathrm{MPa}$ \\
Ti-43.7Al-4.2Nb-0.5Mo-0.2C-0.2B $[17,21]$ & $950^{\circ} \mathrm{C} / 8.3 \times 10^{-4} \mathrm{~s}^{-1}$ & $\delta=1650 \%, \sigma_{30 \%}=60 \mathrm{MPa}$ \\
& $900^{\circ} \mathrm{C} / 8.3 \times 10^{-4} \mathrm{~s}^{-1}$ & $\delta=1220 \%, \sigma_{30 \%}=130 \mathrm{MPa}$ \\
\hline
\end{tabular}

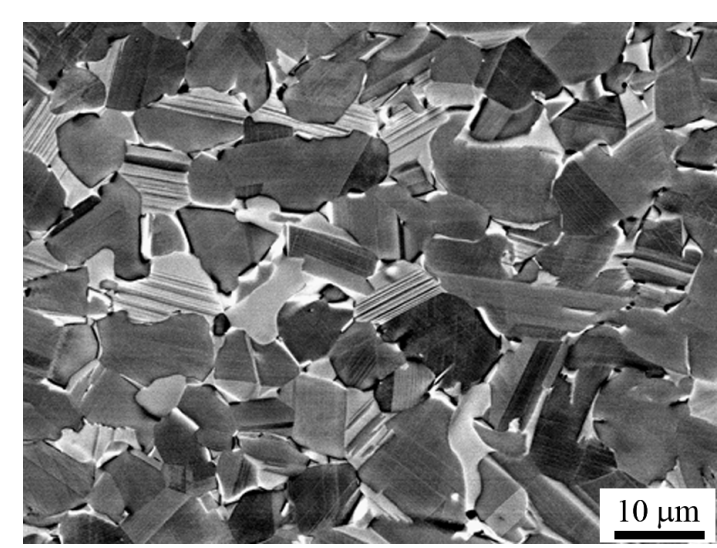

a

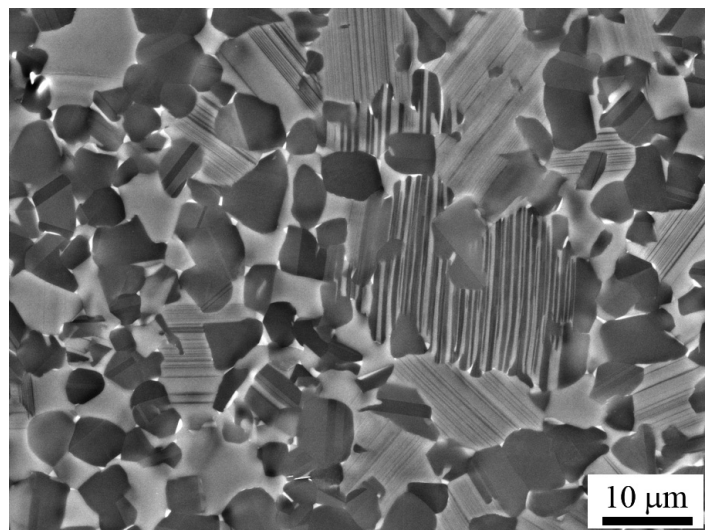

b

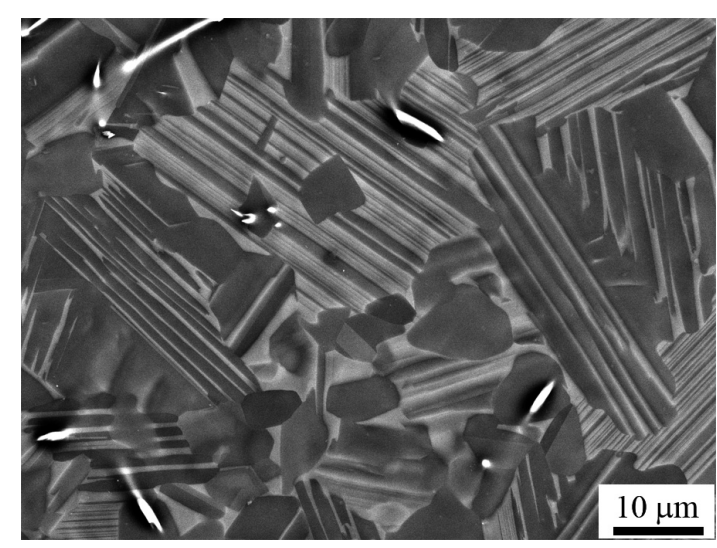

c

Fig. 3. BSE images obtained after hot forging followed by heat treatment: Ti-45Al-5Nb-1Mo-0.2 (a), Ti-43.7Al-4.2Nb-0.5Mo-0.2C-0.2B (b), and Ti-44Al-5Nb-0.2B (c). 
been shown [17,21], high superplastic properties were attained owing to unusually slow dynamic grain growth during superplastic flow. This was supported by a high content of the $\alpha_{2}-\mathrm{Ti}_{3} \mathrm{Al}$ phase, alloying with niobium and dynamic recrystallization/globularization during superplastic flow leading to transformation of remnant lamellar colonies into fine grained structure.

Table 4 shows the tensile properties obtained for the alloys after hot forging followed by heat treatment. One can see that quite reasonable tensile properties were reached in comparison with those obtained after high-temperature forging in similar alloys. Particularly the highest room temperature ductility was obtained in the Ti45 alloy.

Thus, hot forging of $\beta$-solidifying alloys can be successfully carried out at lower temperatures, in the ordered phase field. Hot forging at lower temperatures imparts higher strain energy that leads to a fine-grained structure. The $\beta$-solidifying alloys, particularly the Ti43.7 alloy, showed excellent superplastic properties in the as-forged condition. A higher amount of the $\alpha_{2}$ phase, alloying with niobium and dynamic recrystallization/globularization processes during superplastic flow increased the microstructural stability and promoted attaining superior elongations ( $\gg 1000 \%)$ in this alloy at moderate temperatures [17,21]. At the same time, a higher content of the $\alpha_{2}$ phase and the carbon addition most probably had a negative influence on the room temperature ductility. Indeed, near the same duplex structures were obtained in the Ti43.7 and Ti45 alloys after forging followed by heat treatment. Therefore, the fact that the Ti43.7 alloy showed a lower room temperature ductility than the Ti45 alloy is associated with a negative influence of a higher content of the $\alpha_{2}$ phase and the carbon addition. On the whole, the hot forging at lower temperatures followed by heat treatment gave quite reasonable tensile properties as compared with those obtained after high-temperature hot forging followed by heat treatment. Note that even upset forging at lower temperatures to a strain value as small as $e \approx 0.2$ followed by heat treatment was found quite effective for transformation of nearly lamellar as-cast structure into duplex structure. This confirms the assumption stated in the introduction that a higher strain energy can be imparted during forging in the ordered phase field due to a higher intensity of deformation as compared with forging at higher temperatures in the $\alpha+\gamma+\beta\left(\beta_{\mathrm{o}}\right)$ or $\alpha+\beta$ phase field.

\section{Conclusions}

It has been demonstrated that $\beta$-solidifying $\gamma$-TiAl alloys can be successfully forged at lower temperatures in the ordered phase field. This is cost effective because the forging dies made a Ni-base superalloy without any protective atmosphere can be used. Hot forging at lower temperatures imparted higher strain energy and led to more effective microstructural refinement than forging at higher temperatures. That provided formation of fine-grained conditions in the $\beta$-solidifying $\gamma$-TiAl alloys suitable for superplastic forming

Table 4. Tensile properties of the alloys under study after forging at lower temperatures and heat treatment as compared to those obtained after forging at higher temperatures and heat treatment.

\begin{tabular}{|c|c|c|c|c|c|}
\hline \multirow{3}{*}{ Alloy } & \multirow{3}{*}{ Processing / Microstructure } & \multicolumn{4}{|c|}{ Tensile properties } \\
\hline & & \multicolumn{2}{|c|}{$20^{\circ} \mathrm{C}$} & \multicolumn{2}{|c|}{$700^{\circ} \mathrm{C}$} \\
\hline & & UTS, MPa & $\delta, \%$ & UTS, MPa & $\delta, \%$ \\
\hline Ti-45Al-5Nb-1Mo-0.2B & $\begin{array}{c}\mathrm{HF}(e \approx 1.2)+\mathrm{HT} 1250^{\circ} \mathrm{C} \mathrm{FC}, \\
900^{\circ} \mathrm{C} / \mathrm{DP}, V_{L} \approx 20 \%\end{array}$ & 860 & 3.1 & 790 & 6.5 \\
\hline Ti-43.7Al-4.2Nb-0.5Mo-0.2C-0.2B & $\begin{array}{c}\mathrm{HF}(e \approx 4)+\mathrm{HT} 1200^{\circ} \mathrm{C} \mathrm{FC}, \\
900^{\circ} \mathrm{C} / \mathrm{DP}, V_{L} \approx 20 \%\end{array}$ & 930 & 1.4 & 774 & 3.9 \\
\hline Ti-44Al-5Nb-0.2B & $\begin{array}{c}\text { Forging }(e \approx 0.2)+\mathrm{HT} 1250^{\circ} \mathrm{C} \mathrm{FC} \text {, } \\
900^{\circ} \mathrm{C} / \mathrm{DP}, V_{L} \approx 60 \%\end{array}$ & 730 & 1.25 & 706 & 4.9 \\
\hline \multicolumn{6}{|c|}{ Tensile properties obtained after high-temperature hot forging followed by heat treatment } \\
\hline \multirow{2}{*}{$\mathrm{Ti}-44.5 \mathrm{Al}-6.3 \mathrm{Nb}-0.8 \mathrm{Mo}-0.1 \mathrm{~B}[8]$} & $\begin{array}{c}\mathrm{HF}(e=1-1.2)+\mathrm{HT} 1270^{\circ} \mathrm{C} \mathrm{FC} \\
800^{\circ} \mathrm{C} / \mathrm{DP}\end{array}$ & 800 & 1.5 & 920 & 7.5 \\
\hline & $\begin{array}{c}\mathrm{HF}(e=1-1.2)+\mathrm{HT} 1270^{\circ} \mathrm{C} \mathrm{AC} \\
800^{\circ} \mathrm{C} / \mathrm{DP}\end{array}$ & 970 & 1 & 680 & 3.5 \\
\hline \multirow{2}{*}{ Ti-43.5Al-4Nb-1Mo-0.1B [2] } & $\mathrm{HF}+\mathrm{HT} 1230^{\circ} \mathrm{C} \mathrm{AC,} 950^{\circ} \mathrm{C} / \mathrm{NL}$ & 815 (YS) & 2.2 & - & - \\
\hline & $\mathrm{HF}+\mathrm{HT} 1230^{\circ} \mathrm{C} \mathrm{AC,} 950^{\circ} \mathrm{C} / \mathrm{NL}$ & 950 (YS) & 1 & - & - \\
\hline Ti-43Al-6Nb-1B [9] & $\mathrm{HF}+\mathrm{HT} 1320^{\circ} \mathrm{C}, 1250^{\circ} \mathrm{C} \mathrm{FC} / \mathrm{NL}$ & 820 & 2.4 & - & - \\
\hline
\end{tabular}

HF — hot forging, HT - heat treatment, DP — duplex structure, $V_{L}$ - the volume fraction of lamellar colonies, NL — nearly lamellar structure, YS - yield strength. 
at $900 \ldots 1000^{\circ} \mathrm{C}$. Homogeneous duplex microstructures were obtained after forging at lower temperatures followed by heat treatment. This provided quite reasonable tensile properties as compared with those obtained after high-temperature hot forging followed by heat treatment.

Acknowledgements. The Ti-45Al-5Nb-1Mo-0.2B and Ti-43.7Al-4.2Nb-0.5Mo-0.2C-0.2B ingot materials were obtained from the GfE Metalle und Materialien (Germany) that is gratefully acknowledged. The work was supported by the State Assignment of the Institute for Metals Superplasticity Problems of the Russian Academy of Sciences (No. AAAA-A17-117041310215-4). The work was performed using the facilities of the shared services centre "Structural and Physical-Mechanical Studies of Materials" at the Institute for Metals Superplasticity Problems of Russian Academy of Sciences.

\section{References}

1. B.P. Bewlay, M. Weimer, T. Kelly, A. Suzuki, P.R. Subramanian. In: Intermetallic-based alloys science, technology and applications (ed. by I. Baker, M. Heilmaier, S. Kumar, K. Yoshimi). Warrendale (PA), TMS, MRS 1516 (2013) pp. 49 - 58. Crossref

2. H. Clemens, S. Mayer. Adv. Eng. Mater. 15, 191 (2013). Crossref

3. V. Küstner, M. Oehring, A. Chatterjee, V. Güther, H.-G. Brokmeier, H. Clemens, et al. In: Gamma titanium aluminides 2003 (ed. by Y.-W. Kim, H. Clemens, A.H. Rosenberger). Warrendale(PA), TMS (2003) pp. 89-96.

4. Y. Jin, J. N. Wang, J. Yang, Y. Wang. Scr. Mater. 51, 113 (2004). Crossref

5. R.M. Imayev, V.M. Imayev, M. Oehring, F. Appel. Intermet. 15, 451 (2007). $\underline{\text { Crossref }}$
6. H. Clemens, W. Wallgram, S. Kremmer, V. Güther, A. Otto, A. Bartels. Adv.Eng. Mater. 10, 707 (2008). Crossref

7. D. Hu, H. Jiang, X. Wu. Intermet. 17, 744 (2009). Crossref 8. S. Bolz, M. Oehring, J. Lindemann, F. Pyczak, J. Paul, A. Stark, T. Lippmann, S. Schrüfer, D. Roth-Fagaraseanu, A. Schreyer, S. Weiß. Intermet. 58, 71 (2015). Crossref

9. N.Z. Niu, Y. Y. Chen, F. T. Kong, J. P. Lin. Intermet. 31, 249 (2012). Crossref

10. Y. Su, F. Kong, Y. Chen, N. Gao, D. Zhang. Intermet. 34, 29 (2013). Crossref

11. E. Schwaighofer, H. Clemens, J. Lindemann, A. Stark, S. Mayer. Mater. Sci. Eng. A. 614, 297 (2014). Crossref

12. F. Appel, M. Oehring, J.D. H. Paul. Adv. Eng. Mater. 8, 371 (2006). Crossref

13. J. D. H. Paul, U. Lorenz, M. Oehring, F. Appel. Intermet. 32, 318 (2013). $\underline{\text { Crossref }}$

14. W. Xu, X. Jin, K. Huang, Y. Zong, S. Wu, X. Zhong, F. Kong, D. Shan, S. Nutt. Mater. Sci. Eng. A. 705, 200 (2017). $\underline{\text { Crossref }}$

15. V.M. Imayev, R.M. Imayev, T.I. Oleneva, T. G. Khismatullin. Phys. Met. \& Metallogr. 106 (6), 641 (2008). Crossref

16. T. I. Nazarova, V. M. Imayev, R. M. Imayev, R. R. Mulyukov. Phys. of Met. \& Metallogr. 117 (10), 1038 (2016). Crossref

17. V.M. Imayev, A. A. Ganeev, R. M. Imayev. Intermet. 101, 81 (2018). Crossref

18. V.M. Imayev, R.M. Imayev, T.G. Khismatullin, T. I. Oleneva, V. Gühter, H.-J. Fecht. Mater. Sci. Forum. $638-642,235$ (2010). $\underline{\text { Crossref }}$

19. V.M. Imayev, T. G. Khismatullin, R.M. Imayev. Phys. of Metals \& Metallogr. 109 (4), 402 (2010). $\underline{\text { Crossref }}$

20. E. Schwaighofer, B. Rashkova, H. Clemens, A. Stark, S. Mayer. Intermet. 46, 173 (2014). Crossref

21. V. M. Imayev, R. M. Imayev, T. I. Nazarova, R. A. Gaisin, A. A. Ganeev. Letters on Materials. 8 (4s), 554 (2018). $\underline{\text { Crossref }}$ 